Running head: STRUCTURAL DEVELOPMENTAL SHIFTS

\title{
Developmental shifts toward structural explanations and interventions for social status disparities
}

\author{
Rebecca Peretz-Lange ${ }^{1}$, Jennifer Perry ${ }^{2}, \&$ Paul Muentener ${ }^{3}$ \\ ${ }^{1}$ Boston University, Department of Psychological and Brain Sciences \\ ${ }^{2}$ Harvard University, Department of Psychology \\ ${ }^{3}$ Tufts University, Department of Psychology
}

Main text: 10,038 words

Corresponding author:

Dr. Rebecca Peretz-Lange

Department of Psychological and Brain Sciences

Boston University

64 Cummington Mall, Boston, MA 02215

rebpl@bu.edu 


\begin{abstract}
As part of their early "essentialist" intuitions, young children view intergroup differences as reflecting groups' intrinsic natures. In the present study, we explore the nature and development of "structural" reasoning, or view of intergroup differences as reflecting groups" extrinsic circumstances. We introduced participants $(n=315$; ages 5-6, 9-10, and adults $)$ to novel intergroup status disparities that could be attributed to either personal or structural causes. Disparities were verbally framed in either intrinsic, neutral or extrinsic terms. We assessed attributions by asking participants to explain the disparities and to offer interventions for them. We also assessed participants' status-based social preferences. We found that attributions shifted from personal to structural over development. Explanations and interventions for the disparities were correlated and related to the same predictors (framing and age) and outcomes (social preferences), although interventions were consistently more structural than explanations. Implications for essentialism, causal reasoning, and social development are discussed.
\end{abstract}

Keywords: essentialism, structural reasoning, causal attribution, social preferences, development, verbal framing 


\section{Developmental shifts toward structural explanations and interventions for social status disparities}

"If the misery of the poor be caused not by the laws of nature, but by our institutions, great is our sin." - Charles Darwin

Charles Darwin recognized that social disparities represented a puzzle for causal reasoning (Darwin, 1909): They could be attributed either to people's intrinsic personal natures or to extrinsic societal structures. Research has largely supported Darwin's view of personal attributions as "sinful": Attributing social disparities to groups' intrinsic natures has been shown to promote racial and ethnic prejudice (Diesendruck \& Menahem, 2015; Mandalaywala et al., 2018), endorsement of the legitimacy of male-female power inequality (Morton et al., 2009), opposition to women's and transgender people's rights (Wilton et al., 2019), support for the societal status quo (Hussak \& Cimpian, 2015), and support for eugenics (Dar-Nimrod et al., 2011). Given the pernicious social consequences of personal attributions, in the current study we examine structural attributions as a causal alternative to personal attributions. We explore the development and nature of personal versus structural attributions for observed social disparities.

Attributions for social disparities have their roots early in development, when children first notice hierarchical social status disparities and may intuitively infer their causes. Even infants readily notice social dominance hierarchies (Mascaro \& Csibra, 2012; Thomsen et al., 2011,2020), and by the preschool years children are aware of intergroup disparities in social power (Mandalaywala, Tai, \& Rhodes, 2020), leadership (Mandalaywala \& Rhodes, 2020), achievement (Del Río \& Strasser, 2012), material resources (Olson et al., 2012; Shutts et al., 2016). Moreover, research on early causal reasoning in the physical domain demonstrates that 
when children notice a reliable pattern, they spontaneously infer a cause that may explain it, rather than conceiving of it as random or causeless (Muentener \& Schulz, 2014; Schulz \& Sommerville, 2006). Thus, in the social domain as well, children who notice that members of one social group are reliably higher-status than members of another might infer a cause to account for this pattern.

In particular, research on early "essentialist" intuitions suggests that children may have a bias toward forming intrinsic personal attributions for observed differences between social categories. According to essentialist intuitions, social categories are natural and objective, and category members share an internal "essence" that gives rise to their observable similarities (see Gelman, 2003 for review). Children hold essentialist beliefs about a variety of social categories, including gender (Taylor, Rhodes, \& Gelman, 2009), race (Hirschfeld, 1998), ethnicity (Segall et al., 2015), spoken language (Kinzler \& Dautel, 2012), and religion (Smyth et al., 2017). Children also incorporate status differences into their essentialist representations of social categories (Diesendruck \& HaLevi, 2006; Del Río \& Strasser, 2011; Rhodes \& Mandalaywala, 2017 for review), though notably they do not essentialize status itself as a category (Davoodi et al., 2020). Critically, although the idea of category membership being caused by an intrinsic personal essence is theoretically central to essentialist construals of social categories (Gelman, 2003), research on children's essentialist reasoning does not directly explore children's intuitive proclivity toward personal versus structural attributions. One reason for this is that essentialism involves more than just this attributional bias; essentialism also involves a constellation of other beliefs, such as beliefs about the heritability, stability, discreteness, objectivity, naturalness, and within-group similarity of categories (Gelman, 2003; Rhodes \& Mandalaywala, 2017 for review). As such, the methods of measuring essentialist beliefs are diverse, and do not all focus 
on children's attributions. Moreover, even measures that might capture whether children attribute category membership to intrinsic causes, such as those that assess children's belief in the heritability or stability of category membership (e.g., Hirschfeld \& Gelman, 1997; Kinzler \& Dautel, 2012), capture whether children do or do not view a category-linked property as intrinsically-caused (e.g., whether it is inherited or not, whether it is stable or not), rather than whether children view the property as intrinsically- or extrinsically-caused. Other essentialism measures, such as tasks where children indicate whether they think an adopted baby will grow up resemble its birthparents or adoptive parents, do focus more directly on whether children view traits as inherited or as shaped by one's environment (Taylor, 1996; Taylor, Rhodes, \& Gelman, 2009), but these tasks have mostly been used in the domain of gender (see Rhodes \& Mandalaywala, 2017 for review). Recent work using an adoption task in the domain of race has found that children reject the idea that racial differences reflect intrinsic causes (Mandalaywala et al., 2019). These differences in essentialism of different categories indicate that essentialism of a given category partly reflects what children have observed or heard about that category rather than only reflecting an underlying conceptual attributional bias (Diesendruck et al., 2013; Rhodes, Leslie, \& Tworek, 2012). We aim to address these limitations in the present study by (1) directly assessing children's personal versus structural attributions for social disparities, viewing structural reasoning as a causal alternative to essentialist reasoning, and (2) using novel categories, about which children have no prior knowledge, to isolate attributional biases from any learned knowledge about particular real-world categories. In sum, we assess personal versus structural attributions for novel social status disparities.

We focus on status in particular because of its broad relevance for a variety of different social categories and its role in the development of social preferences. Children's status-based 
preferences have been demonstrated both with familiar groups (Baron \& Banaji, 2009;

Newheiser \& Olson, 2012; Newheiser et al., 2014; Tropp \& Wright, 2003) and with novel groups (Bigler, Brown, \& Markell, 2001; Horwitz, Shutts, \& Olson, 2014; Nesdale \& Flesser, 2001), as well as across cultures (Davey, 1983; Kowalski \& Lo, 2001; Shutts et al., 2011). However, few studies have explored the conceptual or attributional basis of these preferences. Studies that have explored the conceptual basis of status-based preferences have focused on whether children view status as reflecting people's intrinsic nature (personal attributions) or as reflecting mere luck (Olson et al., 2006; Sigelman, 2012), but have not explored children's capacity to view status disparities as reflecting structural inequalities.

To date, one prior study by Peretz-Lange and Muentener (under review) has assessed children's personal versus structural attributions for novel social status disparities. In this study, five- and six-year-old children were introduced to novel social status disparities in the form of novel groups (e.g., Yellows and Purples) being winners and losers at various novel games (e.g., a hoop game). Critically, the disparities could always be attributed to either intrinsic properties of the groups (e.g., Yellows having strong arms and being good at throwing, unlike Purples who have strong legs and are good at kicking) or to extrinsic properties of the games (e.g., a game only having high-up hoops for throwing-into, but no low-down hoops for kicking-into). Children watched one group earn all the points in each game, becoming dominant in this noble hierarchy. The researchers verbally framed this process in either intrinsic terms (e.g., "Look, the Yellows got a point; Yellows are really good at throwing, not Purples"), extrinsic terms (e.g., "Look, the Yellows got a point; this game has high-up hoops, not low-down ones"), or neutral terms (e.g., "Look, the Yellows got a point"). The researchers then assessed participants' attributions for the victory, and finally, their social preferences for the winning versus the losing group. 
Three findings emerged from this study. First, children provided mostly personal attributions overall, but the verbal framing of the status disparity impacted their attributions: In particular, extrinsic framing led to fewer personal attributions compared to either neutral or extrinsic framing. Second, personal attributions (i.e., viewing the victory as reflecting groups' intrinsic strengths and weaknesses) predicted stronger preferences for the winners compared to structural attributions (i.e., viewing the victory as merely reflecting groups' extrinsic advantages and disadvantages). Finally, as the summation of these two findings, extrinsic framing led to stronger preferences for the winners compared to intrinsic or neutral framing.

Thus, Peretz-Lange and Muentener (under review) provides critical initial evidence of young children's bias toward personal rather than structural attributions for novel status disparities. We use this paradigm in the current study, and we extend this research in two important directions: (1) We assess developmental shifts in these attributions, and (2) we directly investigate how participants' causal explanations for the status disparities relate to their causal interventions to change the disparities. Below, we discuss how each of these research questions advances our understanding of social essentialism and attributional reasoning.

\section{Developmental shifts in personal versus structural attributions for status disparities}

Prior research documenting developmental shifts in essentialism of real-world groups presents a complex set of findings: Essentialist beliefs about gender decline over development (Birnbaum et al., 2010; Taylor, Rhodes \& Gelman, 2009), essentialist beliefs about ethnicity and religion increase over development in some cultures (Birnbaum, 2010; Diesendruck et al., 2013; Smyth et al., 2017) but not in other cultures (Diesendruck et al., 2013), and some research shows that essentialist beliefs about race may increase and then gradually decline (Rhodes \& Gelman, 
2009). These differences suggest that developmental trends in the essentialism of real-world groups reflect not only developmental shifts in essentialist frameworks themselves, but also a variety of cultural inputs, such as parents' language (e.g., generic language, Rhodes, Leslie, \& Tworek, 2012), degree of intergroup exposure (Deeb et al., 2011; Rhodes \& Gelman, 2009; Smyth et al., 2017), and cultural values (Birnbaum et al., 2010; Diesendruck \& Haber, 2009). While essentialism is an intuitive framework, these cues may "trigger" children to apply this framework to a particular category differentially across categories and across development (see discussion in Rhodes \& Mandalaywala, 2017). The use of novel groups in the present study allows us to isolate conceptual shifts in essentialist attributions themselves.

As another motivation for characterizing developmental shifts in attributions for social status disparities, we believe that these findings can also support recommendations for when to introduce children to status disparities. Some diversity education efforts recommend teaching children about status disparities early and often (Paley and the Teaching Tolerance Project, 1998; Zakin, 2012). However, introducing children to status disparities at an age when they have a strong conceptual bias to attribute disparities to personal causes might inadvertently foster prejudice. Indeed, emerging research suggests that young children living in racially more diverse zipcodes express more racial bias compared to children living in more racially homogenous zipcodes, which present fewer opportunities for children to observe race-related status disparities (Mandalaywala et al., 2018; see also Deeb et al., 2011). It is possible that, once children form preferences based on personal attributions for observed status disparities, these preferences may be difficult to override even when children later learn about structural causes of these disparities. While research on conceptual change suggests that children are able to revise their early causal theories when encountering new evidence (Gopnik \& Wellman, 2012), it is not yet known 
whether the attitudes that emerged as a result of this initial theory will also be revised. If not, it may be advisable to try and limit children's exposure to status disparities until children reach an age at which they are conceptually poised to grasp the structural causes of these disparities. The present study will shed light on the developmental trajectory of children's conceptual proclitivity toward personal versus structural causes of status disparities, and of their receptivity to learning about structural causes.

We predicted that personal attributions would decline over development, supported by the limited existing research on the development of essentialism in novel contexts. For example, Rhodes and colleagues (2018) assessed preschoolers' essentialist beliefs about a novel social category, Zarpies. They found that younger preschoolers gave more essentialist responses than older preschoolers across a variety of tasks, suggesting that essentialist intuitions may decline over development. However, this study did not assess children's structural responses or trends in structural reasoning over development. As such, it remains unclear whether children shift to an alternate theory of status disparities or simply discount their essentialist theory. Moreover, the study used a relatively narrow age window (4.5-6 years), limiting its developmental conclusions. A second study by Vasilyeva, Gopnik, and Lombrozo (2018) did compare essentialist with structural reasoning, but used novel properties of familiar groups. In the study, Vasilyeva and colleagues introduced children to novel gender-property associations (boys playing different novel games than girls). They found that the ability to attribute this gender difference to a structural cause increased from ages three and four, to ages five and six, to adulthood. However, while the properties used in this study were novel, the groups were familiar gender categories, and thus participants' attributions, and their developmental trajectory, may reflect their essentialist views of gender in particular. Together, these studies suggest that essentialist 
construals may decline over development in favor of structural construals, but no study directly explores developmental shifts in personal versus structural attributions for novel social disparities.

We directly explored these developmental shifts in the present study. We collected data from three age cohorts: Five- and six-year-old children, nine- and ten-year-old children, and adults. We included five- and six-year-olds following Peretz-Lange and Muentener (under review) who tested children of this age and found that these children had a bias toward personal attributions overall. We included nine- and ten-year-old children because previous research using adoption tasks has found that this is the age at which children are able to acknowledge the role of the environment in shaping people's gender-typical behaviors, rather than assuming gendertypical behaviors reflect only people's intrinsic essences (see review in Eidson \& Coley, 2014). Thus, looking beyond gender, we thought that developmental shifts in personal/structural attributions for novel social differences might similarly be visible when comparing preschoolers with nine- and ten-year-olds. We included adults to more fully capture developmental shifts, and so that our findings could contribute to the literature on essentialist reasoning in adults. Research finds that adults do hold essentialist beliefs about a variety of groups (Bastian \& Haslam, 2002; Haslam, Rothschild, \& Ernst, 2000, 2002; Mandalaywala, Amodio, \& Rhodes, 2018), but because these studies typically focus on essentialist beliefs about real-world groups, it is unclear whether adults' essentialist beliefs are relics of early essentialist theories or whether essentialist theories themselves persist into adulthood. By presenting adults with novel intergroup disparities, we were able to assess their default construals of observed disparities. While we predicted that attributions would grow more structural and less personal over development, we made no a priori predictions about the extent of these reductions -- for example, whether biases 
toward personal attributions would be merely reduced, or fully reversed, among older children and adults.

\section{Relations between explanations and interventions for status disparities}

We also sought to explore the nature of this attributional reasoning by using two methods to assess it, and exploring the relationship between these methods. Research on children's causal reasoning has used a variety of methods to assess children's attributions, including children's free-response explanations ("Why did Josie play on the diving board?" Peretz-Lange \& Muentener, 2019; Seiver, Gopnik, \& Goodman, 2013; “Why did Sally get hungry?” Harris, German, \& Mills, 1996; “Why is this block staying straight?”, Bonawitz et al., 2012), and interventions (“Can you make it so Monkey won’t sneeze?”, Schulz \& Gopnik, 2004; “Can you make Lion laugh?” Butler \& Markman, 2012; “Can you make [the machine] stop?”, Gopnik et al., 2001; "What should Sally have done instead so she wasn't hungry?", Harris et al., 1996). Causal intervention questions indicate the variables that children view as "difference-making" in a causal system (Goddu \& Gopnik, 2020). Just as scientists manipulate the variables we view as causally relevant to an outcome, so too do children, from infancy, rationally select variables to intervene upon to produce an outcome (see Schulz, Kushnir, \& Gopnik, 2007 for review). However, these measures of causal reasoning have not been used to explore children's causal attributions for intergroup differences.

Some social essentialism research has assessed children's explanations for category properties. However, these studies typically focus on explanations that reference the category itself (e.g., "because she is a girl”). While category-referencing explanations like these are meaningful and interesting, they are ambiguous with respect to intrinsic/extrinsic causes. For 
example, "because she's a girl" might mean "because girls have 'girl blood' inside their bodies" or "because girls share similar lived experiences" (see discussion in Vasilyeva \& Lombrozo, 2020). In the present study, we explore explanations that refer to either personal causes (e.g., differences in groups' abilities or bodies) or structural causes (e.g., differences in opportunities or treatment) for intergroup status disparities.

Little research has used children's explanations as a window into their reasoning about the causes of social disparities, and even less research has explored children's interventions for social disparities -- or their ideas about what variables must be changed in order to bring about a changed social outcome. Assessing social interventions will indicate children's causal inferences, as well as reveal the conceptual basis of children's ideas about methods of achieving social change. For example, several social change strategies have been proposed to address racial disparities in police brutality, some targeting police officers' biases (a personal intervention) and others targeting police department funding or access to weapons (a structural intervention). Similarly, several strategies have been used to reduce the gender gap in STEM, with some targeting girls' and women's interests (a personal intervention) and others targeting workplace harassment or family leave policies (a structural intervention). While some research explores whether children intervene to change a social disparity (e.g., Elenbaas \& Killen, 2016; Olson et al., 2011; Rizzo, Elenbaas, \& Vanderbilt, 2018), this research does not explore which causal variables children intervene on to do so, as a window into their causal reasoning. In the present study, we explore whether children offer personal or structural interventions for disparities in order to produce a different social outcome.

Assessing social interventions will also shed light on people's beliefs about the respective malleability of intrinsic and extrinsic causes (essences and structures), advancing basic research 
on essentialist and structural reasoning. While social essentialism research has demonstrated that children and adults view essences as fixed and natural, research has not yet explored whether structures are viewed as similarly fixed and natural, or as more malleable. Just as a "growth mindset" (viewing personal characteristics has malleable rather than fixed) promotes motivation and achievement (Dweck, 2000, 2008, 2015; Yeager et al., 2019), it is possible that a "structural mindset" may have similar benefits if structural barriers are construed as flexible. However, children's ideas about the fixedness or flexibility of structures is not yet well-understood. By exploring whether children view structural or personal causes as more flexible and suitable for intervention, the present research will advance our understanding of structural reasoning.

In the present study, we asked children to both freely explain novel status disparities (“Why did [group] win the game?") and also to freely offer interventions that would yield a different status hierarchy ("What could be different so that the other kind could win?"), following the method used by Peretz-Lange and Muentener (under review). Note that we did not ask, "What would you change...", which might have reflected participants' practical ideas about which factor would be easier for them to change. By asking "What could be different...", we sought to capture participants' conceptual ideas about whether different people or different structures would yield a different outcome, and which factor could conceivably be different from the characters/structures observed. We predicted that, if interventions and explanations both reflect children's causal inferences, then explanations and interventions should be correlated, similar, and related to the same predictors and outcomes. Alternatively, if interventions and explanations both reflect causal inferences but children view structural causes as less fixed (more malleable) than essences, children may be more likely to intervene on structures than on people. 


\section{The present study}

In sum, much research has demonstrated that children essentialize intergroup differences, viewing them as reflecting groups' intrinsic personal natures. However, little research has explored children's capacity to view social differences as reflecting extrinsic structural causes. Moreover, existing research on social essentialism typically uses real-world groups, rather than novel groups, making it difficult to isolate conceptual attributional biases from learned knowledge about the causes of particular social phenomena. In the present study, we explored personal versus structural attributions for novel status disparities.

Modeling our procedure directly after Peretz-Lange and Muentener (under review), we presented younger (5-6 years) and older children (9-10 years), as well as adults (18-23 years), with novel social status disparities that could be rationally attributed to either personal or structural causes. Like Peretz-Lange and Muentener (under review), we verbally framed the disparities in either intrinsic, neutral, or extrinsic terms in three between-subjects conditions. We then assessed participants' attributions for the disparity (using two measures: explanations and interventions) and finally, participants' preferences for the high-status or low-status group (using friendship preference ratings of each group).

We had two primary research questions: First, how do personal versus structural attributions shift over development? In this novel context, any observed developmental shifts reflect conceptual shifts in attributional biases themselves. Characterizing these shifts may help identify the ages at which children are conceptually poised to construe observed disparities as structural, rather than defaulting to the essentialist construals that may drive prejudice. We predicted that structural attributions would increase over development. Second, how do explanations for disparities relate to interventions to address them? Little is known about the 
development of reasoning about methods of social change. By probing causal interventions, which we expected to parallel causal explanations, we explored children's and adults' intuitive approaches to changing social hierarchies.

Finally, in addition to these two new contributions, the current study provided an opportunity to replicate three main findings from Peretz-Lange and Muentener (under review): (a) extrinsic framing leads preschoolers to offer more structural attributions compared to either neutral or intrinsic framing, (b) personal attributions predict social preferences for high-status groups, unlike structural attributions, and (c) extrinsic framing mitigates these social preferences compared to neutral or intrinsic framing .

\section{Method}

\section{Participants}

In total, 315 children and adults participated in the study. Participants were recruited in three separate age cohorts: Young children, older children, and adults. Each sample included 105 participants, following the sample size used in Peretz-Lange and Muentener (under review).

Young children $(n=1055$ - and 6 -year-olds, mean age $=6$ years 0 months, $55 \%$ male and $45 \%$ female) were recruited from local museum settings. We did not collect demographic information about this sample, as per museum policy for researchers, but demographic information about the museum visitor population as a whole indicates that visitors are largely White and from middle- to upper-middle-class families.

Older children $(n=1059$ - and 10-year-olds, mean age $=9$ years 9 months, $40 \%$ male and $60 \%$ female) were recruited from the museum settings described above, as well as from local 
afterschool programs (one in a mostly-White and high-income town, $n=11$, and one from a mostly-Black and low-income town, $n=13$ ).

Adults $(n=105$ college undergraduates, mean age $=19$ years 6 months, $31 \%$ male and $69 \%$ female) were recruited from introductory psychology classes, and received course credit for their participation. Demographic information was collected from this sample and indicated that adult participants were $71 \%$ White.

\section{Materials and Procedure}

The procedure and materials (three sets of slides, comprising the three trials) were adapted from Peretz-Lange and Muentener (under review). Below, we review the procedure, which was identical across age cohorts. The procedure involved three trials, the order of which was counterbalanced. Each trial involved three stages, (1) a familiarization phase, (2) a status differentiation phrase, and (3) a test phase. See Figure 1 for slides from one trial.

Familiarization phase. First, participants were familiarized to novel groups of characters as well as to novel structures. The order of presentation was counterbalanced, such that half of participants were familiarized to the characters first, and half were familiarized to the structures first.

To familiarize participants to the novel groups, the experimenter showed participants a slide featuring two groups of characters (e.g., Fig. 1a). The experimenter referred to the groups by their colors using generic language (e.g., "There are two kinds in this game, the Yellows and the Purples"), and then described an intrinsic biological difference between the groups as it related to a difference in ability (e.g., "Guess what? Yellows have really strong arms, so they're really good at throwing. And Purples have really strong legs so they're really good at kicking"). 
a)

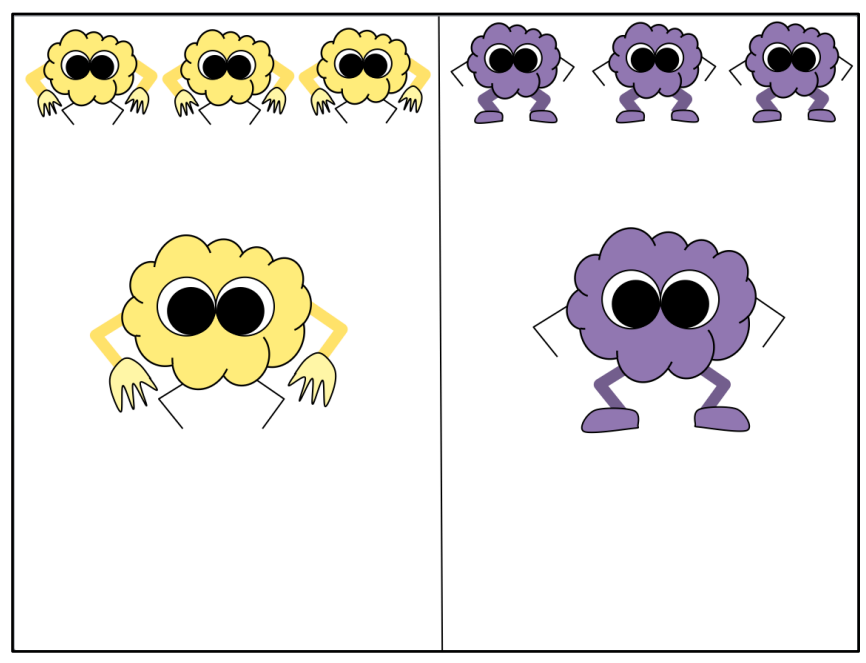

c)

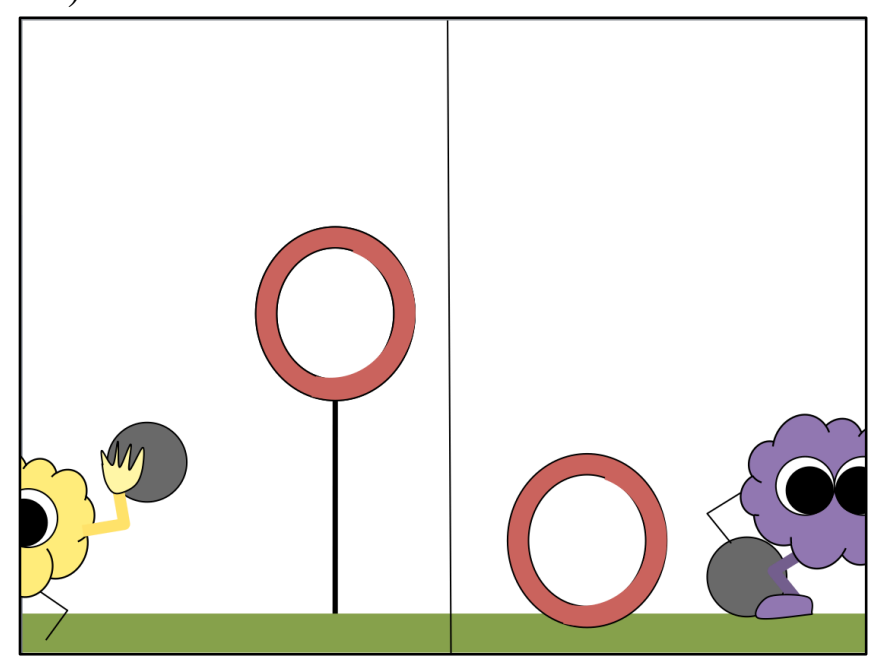

b)

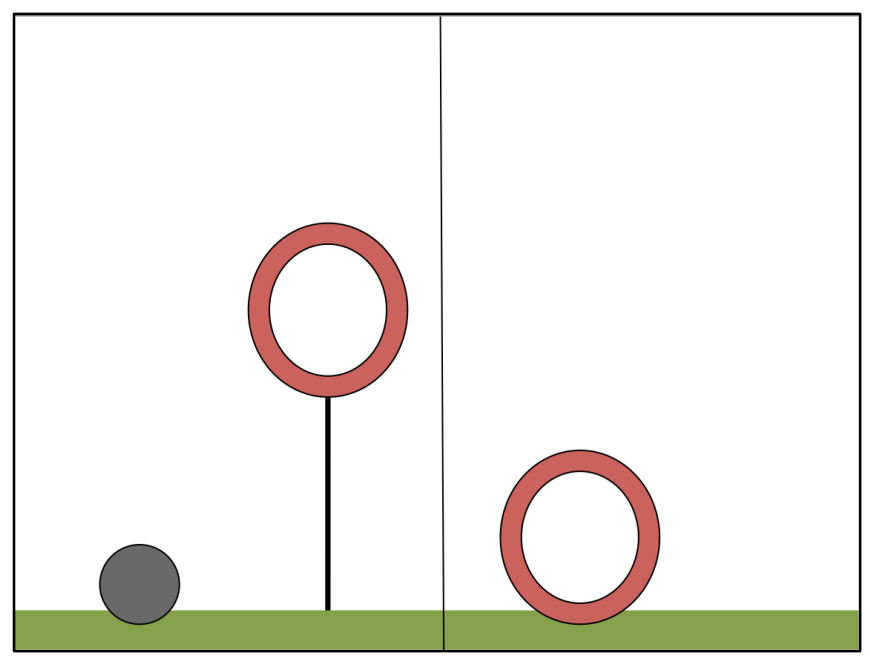

d)

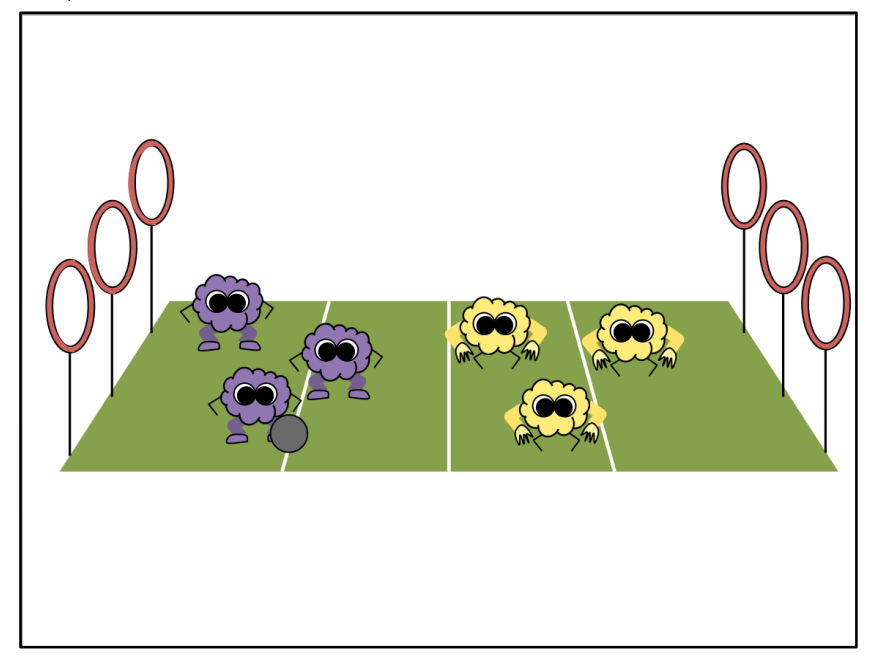

Figure 1. Example set of slides used during (a) familiarization to characters, (b) familiarization to structures, (c) demonstration, and (d) status differentiation process. Note that two more sets of slides were used during the two other trials. 
As a memory check, participants were asked to recall each group's ability (e.g., "So, who is good at throwing? Who is good at kicking?").

To familiarize participants to the novel structures, the experimenter showed participants a slide featuring two structures (e.g., Fig. 1b) described the two structures (e.g., "There are two ways to get points in this game, there are high-up hoops and there are low-down hoops") and an extrinsic structural difference between the structures as it related to a difference in the ability required to interact with them (e.g., "Guess what? High-up hoops are for throwing a ball into. And low-down hoops are for kicking a ball into"). As a memory check, participants were asked to recall each structure's required ability (e.g., "So, which hoop is for kicking? And which hoop is for throwing?")

Finally, both features were demonstrated once (e.g., the Yellow would throw a ball into a high-up hoop, earning a point, and the Purple would kick a ball into a low-down hoop, also earning a point), see Figure 1c.

Status differentiation phase. Next, participants were told, "Ready to watch them play and see who wins?" and they observed the game being played on animated slides (see Fig. 1d). During this process, one extrinsic feature of the game was not useful (e.g., no low-down hoops), and the corresponding intrinsic ability was not useful (e.g., no use for kicking). The game always involved one group making three successful attempts at points, while the other group making three unsuccessful attempts at points, resulting in a decisive 3-0 victory. The color of the winning group (e.g., Yellow or Purple) was counterbalanced within each trial.

Critically, this victory could always be rationally attributed to either a personal cause (characters' bodies or abilities) or a structural cause (structures' forms or required abilities). For example, the Yellows' victory could be attributed to its innate skill at throwing (or to the 
Purples' deficits at this skill), a personal attribution, or alternatively to the presence of high-up hoops (or absence of low-down hoops) in the game, a structural attribution. Both attributions were equally appropriate.

During the game, the verbal framing varied across three between-subjects conditions $(n=$ 35 participants per condition, within each age cohort) to highlight either an intrinsic cause (e.g., "Look, the Yellows got a point! Yellows are good at throwing, not Purples"), extrinsic cause (e.g., "Look, the Yellows got a point! This game has high-up hoops, not low-down ones!"), or neither cause (e.g., "Look, the Yellows got a point!') for the victory. The verbal framing did not vary at any other point during the procedure.

Test phase. Finally, participants were asked a series of questions. First, as a comprehension check, participants were asked to recall the status disparity ("Who won the game?") and responded verbally or by pointing. Next, to assess participants' causal attributions, participants were asked to freely explain the status disparity ("Why do you think they won the game?") and to freely offer an intervention to result in a different status disparity ("What do you think could be different so the other could would win instead?"). Participants who simply restated the victory (e.g., "Because they had more points" or "If the other team had more points") were reprompted (e.g., "Why did they have more points?" or "What could be different so that would happen?”). Finally, participants' social preference ratings of each group were assessed. Participants were first asked whether they would like to be friends with a group; next, children who answered "yes" were asked a follow-up question probing whether they would like to be friends with them "a lot, a medium amount, or a little bit." Participants were then asked to rate the other group similarly, yielding two continuous friendship preference ratings along a fourpoint scale (no, a little, medium, a lot). Note that this continuous friendship preference measure 
marked a divergence from Peretz-Lange and Muentener (under review), who used a binary forced-choice measure. The social preference questions concluded a trial.

Participants completed three trials overall. Each trial involved new groups and new structures: One trial featured the Oranges versus the Blues (one group had speedy hands that were good for climbing up and down, and the other group had speedy feet that were good for running side-to-side) in a capture-the-flag game (involving vertical flagpoles for climbing up and down or horizontal flagpoles for running side-to-side). Another trial featured the Reds versus the Greens (one group was short and good at sliding under, and the other group was tall and good at jumping over) in a race (involving high obstacles for sliding under or low obstacles for jumping over). All trials featured a victory that could be attributed to either a personal or a structural cause.

\section{Results}

\section{Coding}

Responses to explanation and intervention questions were coded as either personal (1), structural (-1), or combinational (0) based on the subject of the response. Responses referring to characters - their bodies, abilities, or behaviors - were coded as personal. Responses referring to the game - its physical components, rules, or required behaviors - were coded as structural. Responses referring to a combination of both the creatures and the game as subjects were coded as combinational, but comprised less than $10 \%$ of responses. Examples of responses from each cohort are provided in Tables 1-3. Responses were summed to compute an explanation score (-3 to 3 ) and an intervention score (-3 to 3 ) for each participant, which were summed in turn to 
create an attribution score (-6 to 6) reflecting participants' overall tendency toward personal or structural attributions.

Responses to friendship preference questions were coded along a four-point scale $(0-3 ; 0$ $=$ no, $1=$ a little, 2 = a medium, 3 = a lot $)$. Next, a difference score $(-3$ to 3$)$ was calculated to represent participants' tendency toward the high-status group (positive scores) or the low-status group (negative scores).

\section{Table 1}

Examples of young children's responses coded as personal, combinational, and structural. All responses presented in Tables 1-3 come from the trial described in the Method section, for ease of interpretation, but note that other trials involved different groups and structures.

\begin{tabular}{|c|c|c|}
\hline & $\begin{array}{l}\text { Explanations } \\
\text { (Responses to "Why did they } \\
\text { win the game?") }\end{array}$ & $\begin{array}{l}\text { Interventions } \\
\text { (Responses to "What could be } \\
\text { different so that the other kind } \\
\text { could win?") }\end{array}$ \\
\hline $\begin{array}{l}\text { Coded as } \\
\text { Personal }\end{array}$ & $\begin{array}{l}\text { "Cause they're good at } \\
\text { throwing" } \\
\text { "Because they have arms" } \\
\text { "Because they have strong } \\
\text { muscles" } \\
\text { "Cause he has stronger arms" } \\
\text { "Because they are stronger at } \\
\text { throwing" }\end{array}$ & $\begin{array}{l}\text { "They'd be good at throwing" } \\
\text { "If they had stronger arms" } \\
\text { "If Purple can throw" } \\
\text { "Make them kick really hard" } \\
\text { "Give them good hands" }\end{array}$ \\
\hline $\begin{array}{l}\text { Coded as } \\
\text { Combinational }\end{array}$ & $\begin{array}{l}\text { "Because they were good at } \\
\text { throwing and the hoops were } \\
\text { up" }\end{array}$ & \\
\hline Coded as Structural & $\begin{array}{l}\text { "Because it was high" } \\
\text { "Because the hoops were tall" } \\
\text { "There were only high hoops" } \\
\text { "Cause that one had throwing } \\
\text { hoops" }\end{array}$ & $\begin{array}{l}\text { "Put the hoops down low" } \\
\text { "Make it a kicking game" } \\
\text { "Move the hoops down" } \\
\text { "If it was the kicking ones" }\end{array}$ \\
\hline
\end{tabular}


Table 2

Examples of older children's responses coded as personal, combinational, and structural.

\begin{tabular}{|c|c|c|}
\hline & $\begin{array}{l}\text { Explanations } \\
\text { (Responses to "Why did they } \\
\text { win the game?") }\end{array}$ & $\begin{array}{l}\text { Interventions } \\
\text { (Responses to "What could be } \\
\text { different so that the other kind } \\
\text { could win?") }\end{array}$ \\
\hline $\begin{array}{l}\text { Coded as } \\
\text { Personal }\end{array}$ & $\begin{array}{l}\text { "Because they have strong } \\
\text { arms and can throw farther." } \\
\text { "Because they scored points } \\
\text { and threw the ball." } \\
\text { "Because they got big strong } \\
\text { arms." } \\
\text { "Because they cheated!" }\end{array}$ & $\begin{array}{l}\text { "Either for Purples to have better } \\
\text { arms or for Yellows to have less } \\
\text { good arms." } \\
\text { "If they also had strong arms like } \\
\text { the Yellow one." } \\
\text { "They'd have to punt it." } \\
\text { "They should stretch out their } \\
\text { legs more." } \\
\text { "If they were better at throwing." }\end{array}$ \\
\hline $\begin{array}{l}\text { Coded as } \\
\text { Combinational }\end{array}$ & $\begin{array}{l}\text { "They have the advantage of } \\
\text { throwing because they have } \\
\text { strong arms and the hoops are } \\
\text { high up." } \\
\text { "Because that was their } \\
\text { skillset; if circumstances were } \\
\text { different, the other kind would } \\
\text { win." } \\
\text { "Because they're better at } \\
\text { throwing but the game doesn't } \\
\text { include the skill that they're } \\
\text { good at." } \\
\text { "Because their arm strength, } \\
\text { but it's kinda impossible for the } \\
\text { Yellows." }\end{array}$ & $\begin{array}{l}\text { "If the hoops were on the ground } \\
\text { or they could kick higher." } \\
\text { "It would be fairer if the } \\
\text { opponents' hoops were present." } \\
\text { "If they put both hoops there or if } \\
\text { the Purples used their very weak } \\
\text { arms." }\end{array}$ \\
\hline $\begin{array}{l}\text { Coded as } \\
\text { Structural }\end{array}$ & $\begin{array}{l}\text { "Because the hoops were made } \\
\text { for them." } \\
\text { "Because all the hoops were up } \\
\text { high so that was really unfair." } \\
\text { "Because most of the game } \\
\text { was you had to throw the ball." } \\
\text { "Again, it was totally rigged." }\end{array}$ & $\begin{array}{l}\text { "Because the hoops were made } \\
\text { for them." } \\
\text { "Have low and high, or put it in } \\
\text { the middle." } \\
\text { "If one side is low hoops and the } \\
\text { other side is high hoops." } \\
\text { "Lower hoops." } \\
\text { "It would be fairer if the } \\
\text { opponents' hoops were present." }\end{array}$ \\
\hline
\end{tabular}


Table 3

Examples of adults' responses coded as personal, combinational, and structural.

\begin{tabular}{|c|c|c|}
\hline & $\begin{array}{l}\text { Explanations } \\
\text { (Responses to "Why did they } \\
\text { win the game?") }\end{array}$ & $\begin{array}{l}\text { Interventions } \\
\text { (Responses to "What could be } \\
\text { different so that the other kind } \\
\text { could win?") }\end{array}$ \\
\hline $\begin{array}{l}\text { Coded as } \\
\text { Personal }\end{array}$ & $\begin{array}{l}\text { "Because they're better at } \\
\text { throwing than the Purples." } \\
\text { "Cause they're the only ones } \\
\text { that could throw." } \\
\text { "Because they can get it in } \\
\text { because of their hands." }\end{array}$ & $\begin{array}{l}\text { "If they were better at throwing." } \\
\text { "If the Purples also had longer } \\
\text { arms." } \\
\text { "They'd need to have strong } \\
\text { enough arms to throw the ball." } \\
\text { "If they had better hands or could } \\
\text { kick higher." }\end{array}$ \\
\hline $\begin{array}{l}\text { Coded as } \\
\text { Combinational }\end{array}$ & $\begin{array}{l}\text { "Because the hoops were } \\
\text { meant for throwing balls into } \\
\text { and only the Yellow can do } \\
\text { that." } \\
\text { "Because they had an } \\
\text { evolutionary advantage. It } \\
\text { seems like the game was set up } \\
\text { for the Purples to win." } \\
\text { "Because they had better arms } \\
\text { and the game required better } \\
\text { throwing skills." }\end{array}$ & $\begin{array}{l}\text { "Make it an even number of low } \\
\text { and high hoops or give them } \\
\text { throwing arms." } \\
\text { "If they also had strong arms or if } \\
\text { the game was different." }\end{array}$ \\
\hline $\begin{array}{l}\text { Coded as } \\
\text { Structural }\end{array}$ & $\begin{array}{l}\text { "Because the hoops were } \\
\text { above the ground, the game } \\
\text { was centered around throwing } \\
\text { instead of kicking." } \\
\text { "All the goals were tall." } \\
\text { "The course was designed for } \\
\text { the balls to be thrown." } \\
\text { "Cause they were testing arm } \\
\text { strength." }\end{array}$ & $\begin{array}{l}\text { "The hoops could be on the } \\
\text { ground." } \\
\text { "Lower hoops." } \\
\text { "Maybe if there was less length } \\
\text { to kick it." } \\
\text { "Their side could be kicking } \\
\text { ones." } \\
\text { "Replace the high hoops with low } \\
\text { ones." }\end{array}$ \\
\hline
\end{tabular}




\section{Developmental shifts in personal versus structural attributions for status disparities}

A linear regression was conducted to determine how age (continuous) and framing condition (categorical; dummy-coded with the neutral condition serving as the reference condition) predicted attribution scores (-6 to 6$)$. The regression was significant $(F(3,280)=17.0$, $\left.\mathrm{R}^{2}=.15, p<.001\right)$, with both age and framing condition accounting for significant variance in attribution scores. As participants got older, they were more likely to offer structural attributions $(B=-.18, p<.001)$. Impacts of verbal framing are reported later in the Results section. No significant interaction was found between age and verbal framing condition; when this interaction was included in a subsequent block of the regression model, it explained no significant additional variance. So, the impact of verbal framing on attributions did not vary significantly across development.

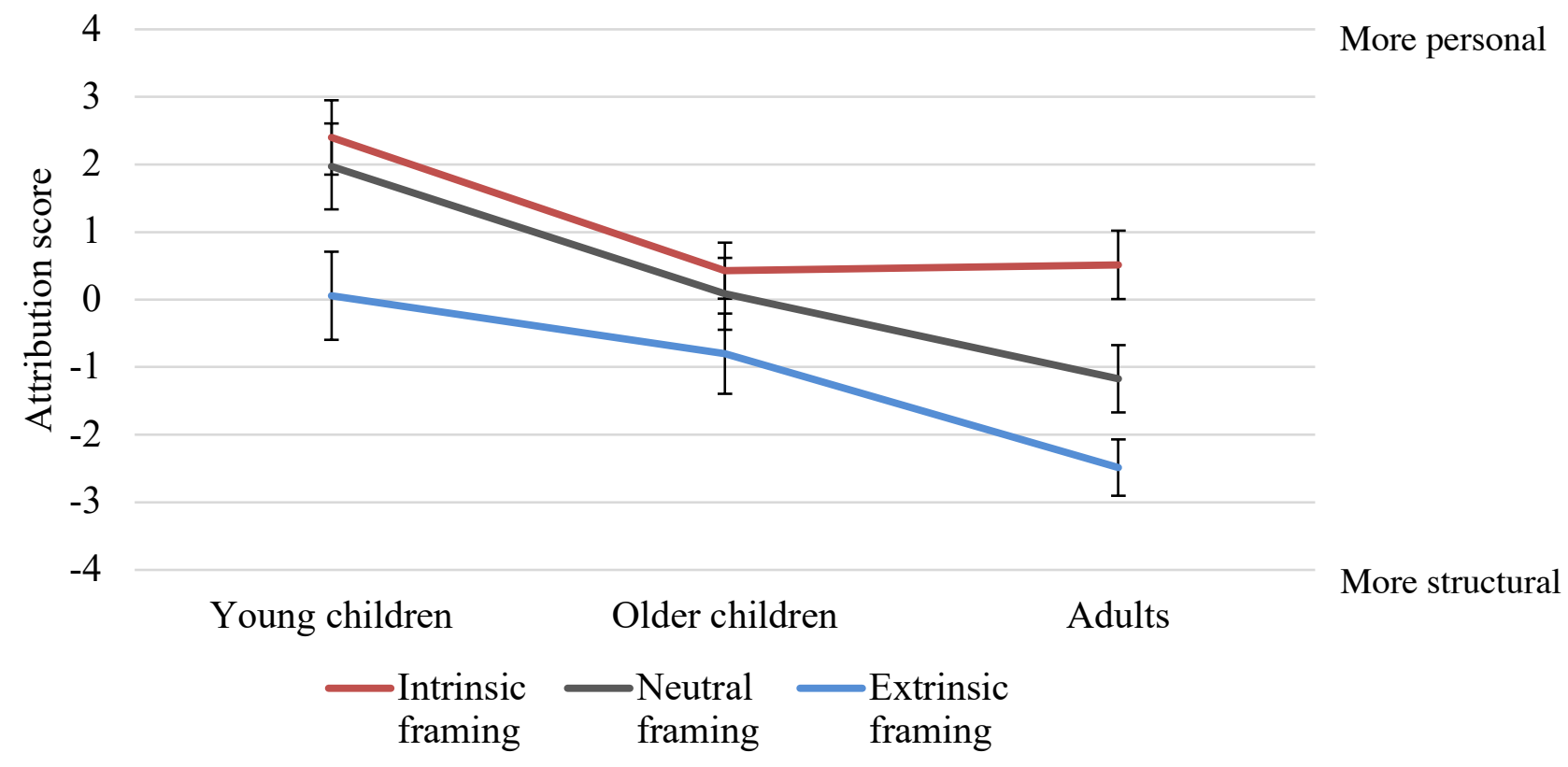

Figure 2. Developmental shifts in attributions, by verbal framing condition. 
Next, to determine each age cohort's overall attributional tendency, separate one-sample t-tests (compared to a score of 0 , representing no attributional bias) were conducted on the attribution scores (-6 to 6) of each cohort. Among young children, the analysis indicated a significant tendency toward personal attributions $(t(104)=4.04, p<.001 ; M=1.48 ; S D=3.74)$. Among older children, the analysis indicated that attribution scores were no different from zero overall, indicating no significant tendency toward either attribution $(M=-.1, S D=3.08, p=.75)$. Finally, among adults, the analysis indicated a significant tendency toward structural attributions $(t(104)=-3.53, p=.001 ; M=-1.05, S D=3.05)$. Although age did not significantly interact with verbal framing to impact attribution scores, we also sought to confirm that this developmental trend was present among just the participants in the neutral framing conditions, across cohorts. These analyses revealed the same pattern of results: Attribution scores among young children in the neutral framing condition were significantly above zero $(t(34)=3.1, \mathrm{p}=.004 ; M=1.97, S D$ $=3.76)$, those from older children were no different from zero $(M=.09, S D=3.15, p=.87)$, and those from adults were significantly below zero $(t(34)=-2.35, p=.025 ; M=-1.17, S D=2.95)$.

Follow-up analyses explored how age separately impacted each of our causal attribution measures, explanations and interventions. When the above regression was conducted on explanation and intervention scores separately, results revealed that increases in age were associated with significant decreases in both explanation scores $(B=-.055, p=.005)$ and intervention scores $(B=-.128, p<.001)$, indicating an age-related shift toward structural responses on both measures. Thus, developmental shifts in attributions reflected both shifts in participants' explanations as well as in their interventions.

In sum, attributions became more structural over development, confirming our hypothesis, and this trend was consistent across both the explanation and intervention measures. 
While we made no a priori hypotheses about the extent of this developmental shift, we found that the early bias toward personal attributions not only lessened over development, but actually reversed, such that adults showed an overall bias toward structural attributions. Attributions thus shifted from personal to structural over development.

\section{Relations between explanations and interventions for status disparities}

To characterize relations between explanations and interventions, we first conducted correlations between participants' explanation scores (-3 to 3) and intervention scores (-3 to 3 ). This correlation was significant and positive among young children $(R=.383, p<.001)$, older children $(R=.32, p=.001)$, and adults $(R=.311, p=.002)$. Notably, these correlations persisted even when verbal framing condition was held constant (i.e., in regression analyses including condition as a predictor; young children, $p<.001$; older children, $p=.001$; adults, $p=.016$ ). This suggests that individual differences in participants' preexisting attributional biases, over and above the differences due to verbal framing condition, may have shaped participants' responses to both questions. In sum, consistent correlations were found between explanations and interventions, supporting our hypothesis.

As part of our hypothesis that explanations and interventions would both reflect causal inferences, we predicted that both measures would be related to the same predictors (i.e., verbal framing and age) and outcomes (i.e., social preferences). To investigate the predictors of responses to each measure, we conducted two linear regressions: A linear regression investigating whether verbal framing (categorical and dummy-coded with the neutral condition serving as the reference condition) and age (continuous) predicted explanation scores ( -3 to 3 ) was significant $\left(F(3,280)=15.2, \mathrm{R}^{2}=.14, p<.001\right)$, with both factors accounting for significant 


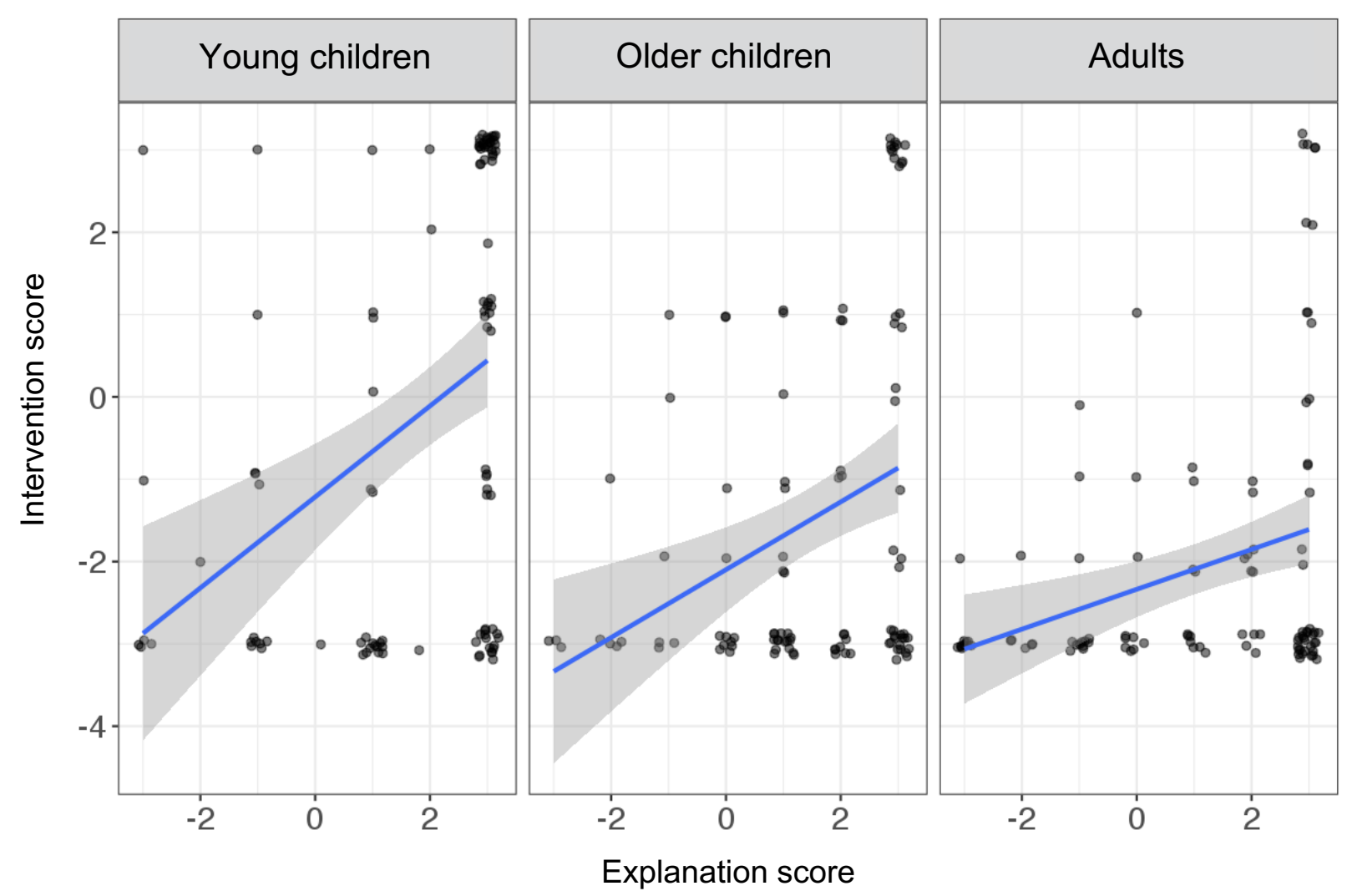

Figure 3. Correlations between explanations and interventions, by age cohort. Bands represent $95 \%$ confidence intervals.

variance in attribution scores (extrinsic framing relative to neutral: $t=-3.48, p<.001$; intrinsic framing relative to neutral: $t=2.56, p=.01$; age: $t=-2.81, p=.005$ ). A linear regression investigating whether these factors predicted intervention scores (-3 to 3$)$ was also significant $\left(F(3,280)=11.4, \mathrm{R}^{2}=.11, p<.001\right)$, and again, both verbal framing and age accounted for significant variance in intervention scores (extrinsic framing relative to neutral: $t=-1.94, p=$ .05 ; intrinsic framing relative to neutral: $p>.05$; age: $t=-5.33, p<.001$ ). Thus, both explanations and interventions were impacted by the same predictors, verbal framing and participant age, confirming our hypothesis. We then tested our hypothesis that both measures would predict social preference scores (-6 to 6). Two linear regression analysses, investigating 
whether explanation scores and intervention scores respectively predicted social preference scores (-3 to 3), were both significant (Explanations: $F(1,313)=56.3, \mathrm{R}^{2}=.153, p<.001$; Interventions: $\left.F(1,313)=54.3, \mathrm{R}^{2}=.148, p<.001\right)$. In sum, results indicated that explanations and interventions were related to the same predictors and outcomes, supporting our hypothesis that both measures reflected participants' causal inferences.

In addition to assessing whether explanations and interventions were correlated, we were also interested in whether responses to the two measures were similar. To assess whether participants' overall tendency toward personal or structural responses differed across the two measures, we compared participants' explanation scores (-3 to 3) with their intervention scores (3 to 3 ) using paired-sample t-tests. The analyses revealed that intervention scores were significantly lower than explanation scores, indicating that interventions were more structural than explanations, across young children $(t(104)=7.99, p<.001$, Explanations $M=1.73 S D=$ 1.84, Interventions $M=-.26 S D=2.62)$, older children $(t(104)=13.46, p<.001$, Explanations $M$ $=1.42 S D=1.66$, Interventions $M=-1.51 S D=2.12)$, and adults $(t(104)=14.32, p<.001$, Explanations $M=1.04 S D=2.1$, Interventions $M=-2.09 S D=1.65)$. Thus, while participants' explanation and interventions were correlated, they were not similar, in contrast to our hypothesis. Participants offered personal explanations for why status disparities existed, but they offered structural interventions to address them. In other words, participants understood that a structural change would lead to a different outcome, but still did not view structural factors as explaining why the status disparity existed. 
3

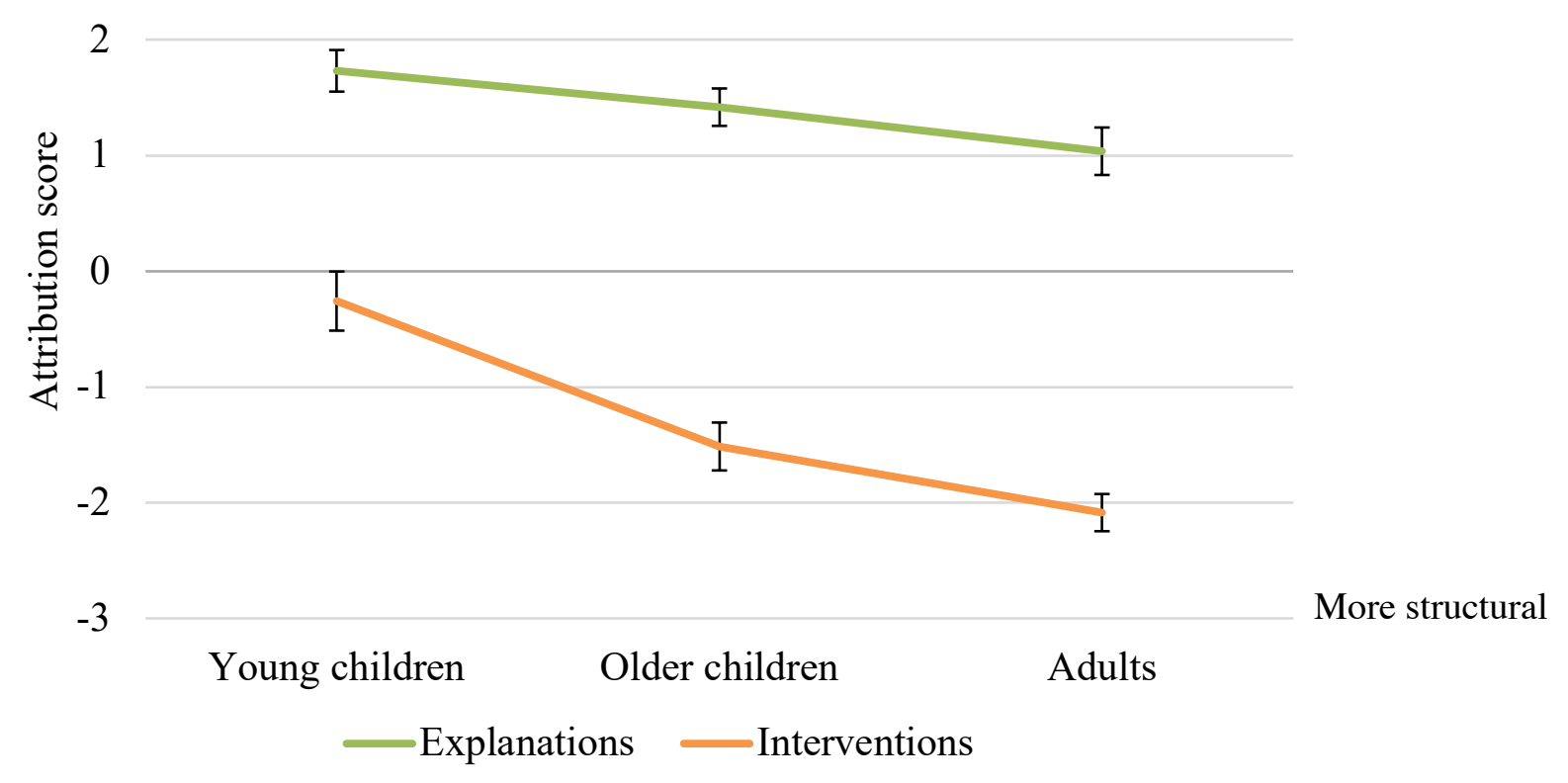

Figure 4. Developmental shifts in explanations and interventions.

Given this robust difference in responses to each measure, we also explored whether this difference shifted over development. A linear mixed model was conducted to how the effect of question type (explanation or intervention) interacted with age cohort to affect participants' responses. The model revealed significant main effects of question type $(F(2,312)=216.67, p<$ $.001)$ and cohort $(F(2,312)=15.61, p<.001)$, as well as a significant interaction between question type and cohort $(F(2,312)=7.04, p=.001)$. There was a greater developmental shift toward structural responses among intervention scores than among explanation scores. Thus, while age-related shifts toward structural responses were evident in both participants' explanations and their interventions, as reported above, these developmental shifts were particularly pronounced among participants' interventions. 


\section{Relations between verbal framing, attributions, and social preferences}

We also sought to examine how (a) verbal framing impacted attributions, (b) how attributions predicted social preferences, and (c) how verbal framing impacted preferences directly. Given that each participant's attributions may have varied between trials, and that we expected attributions to predict preferences within a particular trial, we used multilevel modeling to capture attribution-preference relationships within each trial, accounting for within-subjects variance. This approach contrasts with the analyses reported above, which used attribution scores that pooled each participant's responses across the three trials. Each of the three sets of analyses focused first on relations in just the young child cohort, as we sought to replicate results from young children reported in Peretz-Lange and Muentener (under review), and then on relations in the sample overall. We did not examine the moderating role of age cohort as we made no a priori hypotheses about how age would impact these relations aside from the developmental shifts in attributions reported earlier.

Impact of verbal framing on attributions. Young children's attributions were regressed on onto verbal framing conditions (dummy-coded with the neutral condition serving as the reference condition). Verbal framing significantly impacted attributions such that children in the extrinsic condition made significantly more structural attributions than children in the neutral condition $(b=-0.65, S E=0.29, p=.02)$, but children in the intrinsic condition made attributions that did not differ from the neutral condition $(b=0.14, S E=0.29, p=.62)$. Children in the intrinsic condition also made more personal attributions than children in the extrinsic condition $(b=0.79, S E=0.29, p<.001)$. Thus, verbal framing impacted children's attributions, and this impact was driven by the extrinsic framing condition in particular, supporting our predictions. 
When all cohorts were included in the model, results demonstrated that verbal framing again impacted attributions. Participants in the extrinsic condition again made more structural attributions than those in the neutral condition $(b=-0.45, S E=.16, p=.004)$, and those in the intrinsic condition made marginally more personal attributions than those in the neutral condition $(b=0.30, S E=0.15, p=.05)$. Participants in the intrinsic condition also made more essentialist attributions than those in the extrinsic condition $(b=0.75, S E=0.16, p<.001)$.

Relation between attributions and social preferences. At the trial level, preferences were regressed on attribution scores, first for young children, then across all age cohorts. Among young children, more personal attributions significantly predicted higher preference for the winner $(b=0.13, S E=0.06, p=.04)$, confirming our hypothesis. Including all cohorts, this same relationship was found $(b=0.16, S E=0.03, p<.001)$.

Impact of verbal framing on social preferences. Compared to children in the neutral condition, those in the intrinsic framing condition demonstrated an unexpected preference for the loser $(b=-0.53, S E=.24, p=.027)$, and children's preferences in the extrinsic condition did not differ significantly from those in the neutral condition $(b=-0.25, S E=0.24, p=.29)$ nor from those in the intrinsic condition $(b=0.28, S E=0.23, p=.25)$. Follow-up analyses found that the effect of attributions on preferences did not differ between children in the intrinsic and neutral conditions $(b=-0.04, S E=0.17, p=.81)$, between children in the extrinsic and neutral conditions $(b=0.04, S E=0.15, p=.79)$, nor between children in the intrinsic and extrinsic conditions $(b=0.08, S E=0.16, p=.62)$.

To better understand these unexpected impacts of verbal framing on preferences, we conducted exploratory analyses to descriptively characterize how framing and attributions interacted to impact social preferences. In contrast to our expectation that verbal framing would 
impact preferences through shaping children's attributions, we found that when children made personal attributions following extrinsic framing, they demonstrated stronger preferences for the winner (33 trials; $M=1.0, S E=.24)$ compared to when they made personal attributions following intrinsic framing (47 trials; $M=-.06, S E=.24)$. Similarly, when children made structural attributions following intrinsic framing, they demonstrated less preference for the winner (9 trials; $M=-1.0, S E=.59$ ) compared to when they made structural attributions following extrinsic framing (27 trials; $M=-.16, S D=.27)$. However, small and uneven sample sizes prevented direct comparison, and we recommend caution in interpreting these exploratory analyses.

Including participants across all age cohorts, verbal framing did not impact social preferences overall. Preferences did not differ between the neutral and intrinsic conditions $(b=$ $0.13, S E=.13, p=.31)$, between the neutral and extrinsic conditions $(b=-0.11, S E=.12, p=$ $.38)$, nor between the intrinsic and extrinsic conditions $(b=0.02, S E=.13, p=.89)$.

\section{Discussion}

While much research has documented children's early "essentialist” construals of observed intergroup differences, little research has explored children's capacity to construe observed differences as structural. Moreover, little research has used novel groups to isolate these conceptual biases from children's learned knowledge about particular real-world groups. In the present study, we introduced participants (ages 5-6, 9-10, and adults) to novel social status disparities that could be attributed to either personal or structural causes. We assessed participants' personal and structural attributions for the disparities by asking participants to 
explain the disparities and to offer interventions for them, two measures drawn from the causal reasoning literature.

We found that (1) attributions shifted from personal to structural over development, a trend evident in both participants' explanations and their interventions. We also found that (2) explanation and attribution measures were highly correlated and related to the same predictors (i.e., verbal framing and age) and outcomes (i.e., social preferences), though interventions were consistently more structural than explanations across age cohorts. Finally, we replicated findings from Peretz-Lange and Muentener (under review) that (a) verbal framing of the disparities impacted attributions for them, and (b) personal attributions for the disparities predicted social preferences for the high-status group, relative to structural attributions. However, we did not replicate the finding that (c) verbal framing impacted social preferences directly. Implications are discussed below.

\section{Developmental shifts in personal versus structural attributions for status disparities}

Regarding our first research question, we found that personal attributions declined over development in favor of structural attributions, confirming our hypothesis. This developmental trend was evident across both attribution measures, explanations and interventions. Typical essentialism measures focus on whether children do or do not view a property in essentialist terms (i.e., as stable and inherited), rather than whether children view a property in essentialist versus structural terms as in the present study. Here, we demonstrate not only that personal attributions decline over development (as in characterizations of developmental shifts from "promiscuous" to "selective" essentialism, Eidson \& Coley, 2014), but also that structural attributions increase over development. In other words, rather than becoming globally more 
open-minded about the causes of observed intergroup differences, children may increasingly endorse an alternate causal theory of observed differences -- a structural theory -- over development. We demonstrate this in the present study by including structural attributions as an alternative to personal attributions in the current study. Future research should continue to explore the causes, nature, and consequences of structural reasoning as an alternative to essentialist reasoning (see Vasilyeva et al., 2018; Rizzo, Elenbaas, \& Vanderbilt, 2018).

Because these developmental trends were observed using novel groups, about which participants held no prior knowledge, they represent shifts in conceptual attributional biases rather than shifts in knowledge of observed social phenomena. As such, these findings can shed light on existing research on developmental shifts in essentialist reasoning, which primarily uses real-world groups and which finds differences in developmental trends based on the group studied. For example, while essentialist beliefs about gender decline over development (Birnbaum et al., 2010; Taylor, Rhodes \& Gelman, 2009), essentialist beliefs about ethnicity increase over development (Birnbaum, 2010; Diesendruck et al., 2013; Smyth et al., 2017), and essentialist beliefs about race may increase and then gradually decline (Rhodes \& Gelman, 2009). Interpreting these trends in light of the present findings, developmental increases in essentialism of race and ethnicity may reflect cultural messages about these groups rather than shifts in conceptual biases themselves. Future research should explore differences in cultural inputs about the essentialism of ethnicity, race, and gender, which might account for these different developmental trajectories, given that essentialist attributions themselves decline over development, as revealed in the present study.

Notably, while we made no a priori predictions about the extent to which the personal attribution bias would decline over development, we found that that adults showed a significant 
bias toward structural attributions. Although prior research has found that adults show some essentialist tendencies (Eidson \& Coley, 2014; Haslam, Rothschild, \& Ernst, 2000), these studies have used familiar groups. The fact that adults in the current study readily made structural attributions when reasoning about novel groups suggests that adults' essentialism of familiar groups may be relics of earlier beliefs, about groups they first encountered in childhood, rather than reflecting their current conceptual bias. When the disparity is first encountered in adulthood, our results indicate that adults will tend to view it as reflecting structural causes. Future research should continue to explore adults' essentialist reasoning in novel contexts and how it may differ from their early-developed essentialist beliefs about familiar groups.

This developmental trajectory might also support recommendations for when to introduce children to status disparities. In particular, findings suggest that it might be prudent to introduce children to status disparities only once they are conceptually poised to grasp the structural causes of these disparities, or only in settings where these disparities can be thoughtfully framed in structural terms. This proposal contrasts with recommendations to introduce children to social disparities early and often. These recommendations may not take into account the ways that children differ from adults in the conceptual frameworks they intuitively use to interpret the social world. Introducing young children to status disparities in neutral terms (i.e., without explicitly highlighting the counterintuitive structural causes of these disparities) might inadvertently lead children to assume these disparities reflect intrinsic causes. By characterizing these developmental changes, we suggest that older children may be better equipped to view status disparities as reflecting groups' advantages/disadvantages rather than groups' inherent strengths/weaknesses. 


\section{Relations between explanations and interventions for status disparities}

We were also interested in how explanations and interventions for social status disparities related to one another. Explanation and intervention measures are uncommon in research on early social essentialism, despite the fact that (a) these measures are common in research on causal reasoning in other domains (cite), and (b) early essentialist intuitions are purported to centrally involve attributing observed differences to "essences" or intrinsic causes (Gelman, 2003). Instead, typical esssentialism measures (e.g., stability and heritability tasks) probe children's intrinsic attributions somewhat less directly, as these measures are designed to assess beliefs in stability and heritability rather than attributional tendencies. Here, we used two measures drawn from the causal reasoning literature to assess participants' attributions directly.

Supporting our hypothesis that both measures would assess causal inferences, as in the broader causal reasoning literature, we found that explanations and interventions were highly correlated within each age cohort, and were related to the same predictors (i.e., verbal framing and age) and outcomes (i.e., social preferences). Responses to both measures also grew more structural over development, in line with the idea that developmental shifts in attributional biases would lead to shifts in responses to both measures.

Despite the similarities found across both measures, explanations were significantly more personal than interventions, across all age cohorts. Thus, although explanations and interventions were highly correlated, as we predicted, responses to the two measures were not similar. Instead, explanations tended to be personal while interventions tended to be structural, overall. In other words, while participants understood that different structures would yield a different status disparity, they still did not view the structures as explaining why one group was higher-status; instead, they viewed the status disparities as explained by personal causes. This distinction 
between the kinds of causes referenced in explanations versus interventions in our study is a feature of the fact that both personal and structural causes could account for the presented disparity. In contrast, typical causal reasoning studies present a monocausal system and investigate whether children can infer the single cause accounting for the observed outcome (e.g., Gopnik et al., 2001; Sobel et al., 2007). Our findings suggest that, when presented with a multicausal system such as a social status system, the causes referenced in explanations versus interventions might diverge.

We interpret this difference across the two measures as reflecting participants' view of personal qualities as inflexible, compared to structures. Viewing personal traits as stable, natural, and immutable is a component of essentialist reasoning, but little research has explored whether people view structures as similarly natural and inflexible. While we did not specifically assess participants' views of the flexibility of personal and structural causes respectively, findings suggest that children and adults may view structures as more mutable and suitable for intervention compared to personal qualities. One implication of viewing structures as flexible may be that structural construals of status could have positive impacts on motivation and achievement -- similar to the demonstrated benefits of "growth mindset" (viewing personal qualities as mutable) over "fixed mindset" (Dweck, 2000, 2008, 2015; Yeager et al., 2019). If children view structures as fixed, then a "structural mindset" might be demotivating; however, because our findings suggest that children intuitively view structural barriers as somewhat mutable, this mindset may actually enhance motivation (Goudeau \& Croizet, 2017). Future research should continue to explore children's views of structures as natural or flexible, and the downstream implications of viewing structural properties as less fixed than personal properties. 
More broadly, basic research should seek to understand how structural construals differ from essentialist construals beyond the different attribution involved in each.

An alternative explanation for the difference we observed between explanations and interventions might be that this difference reflects an order effect, given that the two attribution questions were presented in a fixed order. However, we believe it is unlikely that the order of the attribution questions impacted responses. Classic causal reasoning studies have presented both questions in a fixed order and found similar responses across both questions (e.g., Harris, German, \& Mills, 1996, "Why did Sally's fingers get inky? ... What should Sally have done instead so that her fingers wouldn't get inky?"; Butler \& Markman, 2012, "What makes lion laugh? ... Can you give Lion an animal to make him laugh?"). Moreover, research has shown that prompting children to offer explanations supports their causal inferences (Legare \& Lombrozo, 2014; Walker, Lombrozo, Legare, \& Gopnik, 2014), because the process of explaining a given phenomenon constrains the causal hypotheses children entertain for it (Walker et al., 2017). Thus, if anything, we would have expected explanations to entrench children's reasoning about interventions. The fact that children offered interventions that differed from the explanations they had just offered is therefore particularly surprising.

Another alternative explanation for the difference observed between explanations and interventions may be that the status differentiation phase of the procedure was biased toward structural interventions: The game involved only high-up hoops (low-down hoops were not present), but involved both groups of characters. Thus, perhaps it was easier for participants to imagine including the structure not featured. However, we argue that insofar as their relations to status, the structures and characters were equally salient: Only high-up hoops were relevant for earning points, and only strong arms were relevant for earning points. Put differently, earning 
points required a match between a group's intrinsic abilities and the game's extrinsic features. Thus, changing either the characters or the structures would be equally effective interventions. Although it may be easier to imagine changing a hoop than changing a character, we argue that this reflects people's beliefs about the fixedness of structures versus people, rather than being an artifact of the procedure. Moreover, if the procedure had truly been biased toward structural causes overall, this would have been evident in participants' explanations as well -- instead, participants across cohorts tended to say the disparities existed "because of" characters' personal qualities. In sum, we interpret participants' structural interventions as reflecting their construal of characters less mutable than structures, rather than as reflecting a biased procedure.

\section{Relations between verbal framing, attributions, and social preferences}

The current study also provided an opportunity to replicate the findings from PeretzLange and Muentener (under review), who used a similar procedure to study five- and six-yearolds only. We replicated their finding that young children provided mostly personal attributions overall, as well as their finding that verbal framing impacted attributions. In particular, PeretzLange and Muentener (under review) found that extrinsic framing reduced young children's personal attributions relative to both intrinsic and neutral framing, which yielded similar rates of attributions. We replicated this asymmetric impact of framing among young children, supporting the idea that young children hold a default bias toward personal attributions that can be disrupted by extrinsic framing, but not enhanced by intrinsic framing (see also, Peretz-Lange \& Muentener, 2019).

We also replicated the finding that personal attributions for status predicted preferences for high-status groups, relative to structural attributions. This relationship was consistent across 
age cohorts. Children and adults who construed status disparities as reflecting groups' intrinsic strengths and weaknesses preferred the high-status group, but those who construed the status disparities as reflecting groups' extrinsic advantages and disadvantages did not show this preference. Attributions for status disparities have been shown to impact adults' social preferences (Mandalaywala, Amodio, \& Rhodes, 2018), but here we show that attributions also shape social preferences early in development. Moreover, while previous research on the relationship between attributions and social preferences has used familiar groups (see Rhodes \& Mandalaywala, 2017 for review), here we demonstrate this relationship using novel groups. In doing so, we show that attributions may contribute to the initial emergence of social preferences, rather than only reinforcing existing preferences. The scant existing research using novel groups to explore the relationship between children's essentialist reasoning and social preferences finds few effects (Rhodes et al., 2018) though this research provided no information about groups' status (see discussion of this limitation in Rhodes \& Mandalaywala, 2017). Here we show that personal versus structural attributions for status disparities relate to early preferences for novel high- versus low-status groups.

Despite finding that (a) verbal framing impacts attributions and that (b) attributions predict social preferences, we did not find evidence that (c) verbal framing impacts social preferences directly, as in Peretz-Lange and Muentener (under review). In fact, young children in the personal framing condition actually preferred the loser, unlike children in the neutral framing condition who preferred the winner. Given that this direct effect is theoretically the summation of the previous two effects, this pattern of results was unexpected. Below, we discuss two possible explanations for this set of results: 
One possibility is that the attributions that predicted social preferences were not those that were offered as a result of the verbal framing received, but were rather those that were offered in spite of the verbal framing received. Indeed, post-hoc analyses indicated that, at least among young children, children who made personal attributions following extrinsic framing had stronger preferences for the winner compared to children who made personal attributions following intrinsic framing. Similarly, children who made structural attributions following intrinsic framing had stronger preferences for the winner compared to children who made structural attributions following extrinsic framing. These results suggest that individual differences in young children's preexisting attributional biases may have informed their statusbased preferences, beyond the differences due to verbal framing. The idea of robust individual differences in attributional biases is also supported by our finding that explanations and interventions correlated even when verbal framing condition was held constant. Results indicate that young children may even be reactive against verbal framing that does not align with their preexisting attributional biases. Future research is needed to better understand why verbal framing led to these effects. Ultimately, our findings are consistent with our broad proposal that personal/structural attributions for status play a role in the formation of social preferences, but leave open questions about how to manipulate these attributions in a way that has downstream consequences for social preferences.

Another possibility concerns the social preference measures used in this study, and the fact that this aspect of our results diverges from results reported in Peretz-Lange and Muentener (under review). We note one difference between our procedures that may account for this. The present study used two continuous rating scales, allowing us to detect a preference for the winner, a preference for the loser, or no preference. In contrast, Peretz-Lange and Muentener 
(under review) used a forced-choice measure, requiring children to express either a preference for the winner or a preference for the loser. Thus, the participants in our study who expressed no preference, rating both groups equally (as young child participants did on $46 \%$ of trials) would have been forced to choose a group in the original study, and perhaps would have chosen the winning group in this scenario. In other words, it is possible that a slight preference for the highstatus group would have been evident in the original procedure, but not in our procedure.

\section{Conclusion}

The present study explored the nature and development of structural attributions for social status disparities; we viewed these as an alternative to the personal attributions that are part of essentialist reasoning. We presented participants (ages 5-6 years, 9-10 years, and adults) with novel social status disparities that could be attributed to either personal or structural causes. We probed participants' attributions by asking them to explain the disparities and to offer interventions to change the disparities. Results showed that participants conceived the disparity in increasingly structural terms over development, shedding new light on research about shifts in essentialism of real-world categories. Results also showed that structural inferences informed both participants' explanations as well as their interventions. Responses to both explanation and intervention measures were also related to the verbal framing used to describe the disparities, as well as to participants' social preferences for the high- over the low-status groups. Despite these similarities across measures, interventions were consistently more structural than explanations, suggesting that children and adults may conceive of structural properties as more mutable than personal qualities. Future research should continue to explore the development and consequences of viewing low-status groups as extrinsically marginalized rather than intrinsically inferior. 


\section{References}

Baron, A., \& Banaji, M. (2009). Evidence of system justification in young children. Social and Personality Psychology Compass, 3(6), 918-926. https://doi.org/10.1111/j.17519004.2009.00214.x

Bastian, B., \& Haslam, N. (2006). Psychological essentialism and stereotype endorsement. Journal of Experimental Social Psychology, 42(2), 228-235. https://doi.org/10.1016/j.jesp.2005.03.003

Bigler, R. S., Spears Brown, C., \& Markell, M. (2001). When groups are not created equal: Effects of group status on the formation of intergroup attitudes in children. Child Development, 72(4), 1151-1162. https://doi.org/10.1111/1467-8624.00339

Birnbaum, D., Deeb, I., Segall, G., Ben-Eliyahu, A., \& Diesendruck, G. (2010). The development of social essentialism: The case of Israeli children's inferences about Jews and Arabs. Child Development, 81(3), 757-777. https://doi.org/10.1111/j.14678624.2010.01432.x

Bonawitz, E. B., van Schijndel, T. J., Friel, D., \& Schulz, L. (2012). Children balance theories and evidence in exploration, explanation, and learning. Cognitive Psychology, 64(4), 215234. https://doi.org/10.1016/j.cogpsych.2011.12.002

Butler, L. P., \& Markman, E. M. (2012). Finding the cause: Verbal framing helps children extract causal evidence embedded in a complex scene. Journal of Cognition and Development, 13(1), 38-66. https://doi.org/10.1080/15248372.2011.567201

Dar-Nimrod, I., \& Heine, S. J. (2011). Genetic essentialism: on the deceptive determinism of DNA. Psychological Bulletin, 137(5), 800. https://doi.org/10.1037/a0021860 
Darwin, C. (1909). The voyage of the Beagle. P.F. Collier \& Son. https://doi.org/10.5962/bhl.title.98662

Davoodi, T., Soley, G., Harris, P. L., \& Blake, P. R. (2020). Essentialization of social categories across development in two cultures. Child Development, 91(1), 289-306. https://doi.org/10.1111/cdev.13209

Davey, A. (1983). Learning to be prejudiced. London, UK: Edward Arnold.

Deeb, I., Segall, G., Birnbaum, D., Ben-Eliyahu, A., \& Diesendruck, G. (2011). Seeing isn't believing: The effect of intergroup exposure on children's essentialist beliefs about ethnic categories. Journal of Personality and Social Psychology, 101(6), 1139. https://doi.org/10.1037/a0026107

Del Río, M. F., \& Strasser, K. (2013). Preschool children’s beliefs about gender differences in academic skills. Sex Roles, 68(3-4), 231-238. https://doi.org/10.1007/s11199-012-0195-6

Diesendruck, G., Goldfein-Elbaz, R., Rhodes, M., Gelman, S., \& Neumark, N. (2013). Crosscultural differences in children's beliefs about the objectivity of social categories. Child Development, 84(6), 1906-1917. https://doi.org/10.1111/cdev.12108

Diesendruck, G., \& Haber, L. (2009). God's categories: The effect of religiosity on children's teleological and essentialist beliefs about categories. Cognition, 110(1), 100-114. https://doi.org/10.1016/j.cognition.2008.11.001

Diesendruck, G., \& HaLevi, H. (2006). The role of language, appearance, and culture in children's social category-based induction. Child Development, 77(3), 539-553. https://doi.org/10.1111/j.1467-8624.2006.00889.x

Diesendruck, G., \& Menahem, R. (2015). Essentialism promotes children's inter-ethnic bias. Frontiers in Psychology, 6, 1180. https://doi.org/10.3389/fpsyg.2015.01180 
Dweck, C. S. (2000). Self-theories: Their role in motivation, personality, and development. Psychology press.

Dweck, C. S. (2008). Mindset: The new psychology of success. Random House Digital, Inc..

Dweck, C. (2015). Carol Dweck revisits the growth mindset. Education Week, 35(5), 20-24.

Eidson, R. C., \& Coley, J. D. (2014). Not so fast: Reassessing gender essentialism in young adults. Journal of Cognition and Development, 15(2), 382-392. https://doi.org/10.1080/15248372.2013.763810

Elenbaas, L., \& Killen, M. (2016). Children rectify inequalities for disadvantaged groups. Developmental Psychology, 52(8), 1318. https://doi.org/10.1037/dev0000154

Gelman, S. A. (2003). The essential child: Origins of essentialism in everyday thought. Oxford University Press, USA. https://doi.org/10.1093/acprof:oso/9780195154061.001.0001

Goddu, M. K., \& Gopnik, A. (2020). Learning what to change: Young children use "differencemaking” to identify causally relevant variables. Developmental Psychology, 56(2), 275. https://doi.org/10.1037/dev0000872

Gopnik, A., Sobel, D. M., Schulz, L. E., \& Glymour, C. (2001). Causal learning mechanisms in very young children: Two-, three-, and four-year-olds infer causal relations from patterns of variation and covariation. Developmental Psychology, 37(5), 620.

https://doi.org/10.1037/0012-1649.37.5.620

Gopnik, A., \& Wellman, H. M. (2012). Reconstructing constructivism: Causal models, Bayesian learning mechanisms, and the theory theory. Psychological Bulletin, 138(6), 1085. https://doi.org/10.1037/a0028044

Goudeau, S., \& Croizet, J. C. (2017). Hidden advantages and disadvantages of social class: How 
classroom settings reproduce social inequality by staging unfair comparison. Psychological Science, 28(2), 162-170. https://doi.org/10.1177/0956797616676600

Harris, P. L., German, T., \& Mills, P. (1996). Children's use of counterfactual thinking in causal reasoning. Cognition, 61(3), 233-259. https://doi.org/10.1016/s0010-0277(96)00715-9

Haslam, N., Rothschild, L., \& Ernst, D. (2000). Essentialist beliefs about social categories. British Journal of Social Psychology, 39(1), 113-127. https://doi.org/10.1348/014466600164363

Haslam, N., Rothschild, L., \& Ernst, D. (2002). Are essentialist beliefs associated with prejudice?. British Journal of Social Psychology, 41(1), 87-100. https://doi.org/10.1348/014466602165072

Hirschfeld, L. A. (1998). Race in the making: Cognition, culture, and the child's construction of human kinds. MIT Press. https://doi.org/10.7551/mitpress/5734.001.0001

Hirschfeld, L. A., \& Gelman, S. A. (1997). What young children think about the relationship between language variation and social difference. Cognitive Development, 12(2), 213238. https://doi.org/10.1016/s0885-2014(97)90014-9

Horwitz, S. R., Shutts, K., \& Olson, K. R. (2014). Social class differences produce social group preferences. Developmental Science, 17(6), 991-1002. https://doi.org/10.1111/desc.12181

Hussak, L. J., \& Cimpian, A. (2015). An early-emerging explanatory heuristic promotes support for the status quo. Journal of Personality and Social Psychology, 109(5), 739. https://doi.org/10.1037/pspa0000033

Kinzler, K. D., \& Dautel, J. B. (2012). Children's essentialist reasoning about language and race. Developmental Science, 15(1), 131-138. https://doi.org/10.1111/j.14677687.2011.01101.x 
Kowalski, K., \& Lo, Y. (2001). The influence of perceptual features, ethnic labels, and sociocultural information on the development of ethnic/racial bias in young children. Journal of Cross-Cultural Psychology, 32, 444-455. https://doi.org/10.1177/0022022101032004005

Legare, C. H., \& Lombrozo, T. (2014). Selective effects of explanation on learning during early childhood. Journal of Experimental Child Psychology, 126, 198-212. https://doi.org/10.1016/j.jecp.2014.03.001

Mandalaywala, T. M., Amodio, D. M., \& Rhodes, M. (2018). Essentialism promotes racial prejudice by increasing endorsement of social hierarchies. Social Psychological and Personality Science, 9(4), 461-469. https://doi.org/10.1177/1948550617707020

Mandalaywala, T. M., Ranger-Murdock, G., Amodio, D. M., \& Rhodes, M. (2019). The nature and consequences of essentialist beliefs about race in early childhood. Child Development, 90(4), e437-e453. https://doi.org/10.1111/cdev.13008

Mandalaywala, T. M., \& Rhodes, M. (2020). Gender stereotypes about leadership in early childhood. Preprint retrieved from https://psyarxiv.com/ytsbn/, https://doi.org/10.31234/osf.io/ytsbn

Mandalaywala, T. M., Tai, C., \& Rhodes, M. (2020). Children's use of race and gender as cues to social status. PloS one, 15(6), e0234398. https://doi.org/10.1371/journal.pone.0234398

Mascaro, O., \& Csibra, G. (2012). Representation of stable social dominance relations by human infants. Proceedings of the National Academy of Sciences, 109(18), 6862-6867. https://doi.org/10.1073/pnas.1113194109

Morton, T. A., Postmes, T., Haslam, S. A., \& Hornsey, M. J. (2009). Theorizing gender in the 
face of social change: Is there anything essential about essentialism?. Journal of Personality and Social Psychology, 96(3), 653. https://doi.org/10.1037/a0012966

Muentener, P., \& Schulz, L. (2014). Toddlers infer unobserved causes for spontaneous events. Frontiers in Psychology, 5, 1496. https://doi.org/10.3389/fpsyg.2014.01496

Nesdale, D., \& Flesser, D. (2001). Social identity and the development of children's group attitudes. Child Development, 72(2), 506-517. https://doi.org/10.1111/1467-8624.00293

Newheiser, A. K., \& Olson, K. R. (2012). White and Black American children's implicit intergroup bias. Journal of Experimental Social Psychology, 48(1), 264-270. https://doi.org/10.1016/j.jesp.2011.08.011

Newheiser, A. K., Dunham, Y., Merrill, A., Hoosain, L., \& Olson, K. R. (2014). Preference for high status predicts implicit outgroup bias among children from low-status groups. Developmental Psychology, 50(4), 1081. https://doi.org/10.1037/a0035054

Olson, K. R., Banaji, M. R., Dweck, C. S., \& Spelke, E. S. (2006). Children's biased evaluations of lucky versus unlucky people and their social groups. Psychological Science, 17(10), 845. https://doi.org/10.1111/j.1467-9280.2006.01792.x

Olson, K. R., Dweck, C. S., Spelke, E. S., \& Banaji, M. R. (2011). Children's responses to groupbased inequalities: Perpetuation and rectification. Social Cognition, 29(3), 270-287. https://doi.org/10.1521/soco.2011.29.3.270

Olson, K. R., Shutts, K., Kinzler, K. D., \& Weisman, K. G. (2012). Children associate racial groups with wealth: Evidence from South Africa. Child Development, 83(6), 1884-1899. https://doi.org/10.1111/j.1467-8624.2012.01819.x

Paley, V. G. The Teaching Tolerance Project.(1998). Starting small: Teaching tolerance in 
preschool and the early grades. The Teaching Tolerance Project.

Peretz-Lange, R., \& Muentener, P. (2019). Verbal framing and statistical patterns influence children's attributions to situational, but not personal, causes for behavior. Cognitive Development, 50, 205-221. https://doi.org/10.1016/j.cogdev.2019.05.005

Rhodes, M., \& Mandalaywala, T. M. (2017). The development and developmental consequences of social essentialism. Wiley Interdisciplinary Reviews: Cognitive Science, 8(4), e1437. https://doi.org/10.1002/wcs.1437

Rhodes, M., \& Gelman, S. A. (2009). A developmental examination of the conceptual structure of animal, artifact, and human social categories across two cultural contexts. Cognitive Psychology, 59(3), 244-274. https://doi.org/10.1016/j.cogpsych.2009.05.001

Rhodes, M., Leslie, S. J., Saunders, K., Dunham, Y., \& Cimpian, A. (2018). How does $\quad$ social essentialism affect the development of inter-group relations?. Developmental Science, 21(1), e12509. https://doi.org/10.1111/desc.12509

Rhodes, M., Leslie, S. J., \& Tworek, C. M. (2012). Cultural transmission of social essentialism. Proceedings of the National Academy of Sciences, 109(34), 13526-13531. https://doi.org/10.1073/pnas. 1208951109

Rizzo, M. T., Elenbaas, L., \& Vanderbilt, K. E. (2020). Do children distinguish between resource inequalities with individual versus structural origins?. Child Development, 91(2), 439455. https://doi.org/10.1111/cdev.13181

Schulz, L. E., \& Gopnik, A. (2004). Causal learning across domains. Developmental Psychology, 40(2), 162. https://doi.org/10.1037/0012-1649.40.2.162

Schulz, L. E., \& Sommerville, J. (2006). God does not play dice: Causal determinism and 
preschoolers' causal inferences. Child Development, 77(2), 427-442.

https://doi.org/10.1111/j.1467-8624.2006.00880.x

Segall, G., Birnbaum, D., Deeb, I., \& Diesendruck, G. (2015). The intergenerational transmission of ethnic essentialism: How parents talk counts the most. Developmental Science, 18(4), 543-555. https://doi.org/10.1111/desc.12235

Schulz, L., Kushnir, T., \& Gopnik, A. (2007). Learning from doing: Intervention and causal inference. Causal learning: Psychology, Philosophy, and Computation, 67-85. https://doi.org/10.1093/acprof:oso/9780195176803.003.0006

Shutts, K., Brey, E. L., Dornbusch, L. A., Slywotzky, N., \& Olson, K. R. (2016). Children use wealth cues to evaluate others. PloS One, 11(3), e0149360. https://doi.org/10.1371/journal.pone.0149360

Shutts, K., Kinzler, K. D., Katz, R. C., Tredoux, C., \& Spelke, E. S. (2011). Race preferences in children: Insights from South Africa. Developmental Science, 14(6), 1283-1291. https://doi.org/10.1111/j.1467-7687.2011.01072.x

Seiver, E., Gopnik, A., \& Goodman, N. D. (2013). Did she jump because she was the big sister or because the trampoline was safe? Causal inference and the development of social attribution. Child Development, 84(2), 443-454. https://doi.org/10.1111/j.14678624.2012.01865.x

Sigelman, C. K. (2012). Rich man, poor man: Developmental differences in attributions and perceptions. Journal of Experimental Child Psychology, 113(3), 415-429. https://doi.org/10.1016/j.jecp.2012.06.011

Smyth, K., Feeney, A., Eidson, R. C., \& Coley, J. D. (2017). Development of essentialist 
thinking about religion categories in Northern Ireland (and the United States). Developmental Psychology, 53(3), 475. https://doi.org/10.1037/dev0000253

Sobel, D. M., Yoachim, C. M., Gopnik, A., Meltzoff, A. N., \& Blumenthal, E. J. (2007). The blicket within: Preschoolers' inferences about insides and causes. Journal of Cognition and Development, 8(2), 159-182. https://doi.org/10.1080/15248370701202356

Taylor, M. G. (1996). The development of children's beliefs about social and biological aspects of gender differences. Child Development, 67(4), 1555-1571. https://doi.org/10.2307/1131718

Taylor, M. G., Rhodes, M., \& Gelman, S. A. (2009). Boys will be boys; cows will be cows: Children's essentialist reasoning about gender categories and animal species. Child Development, 80(2), 461-481. https://doi.org/10.1111/j.1467-8624.2009.01272.x

Tropp, L. R., \& Wright, S. C. (2003). Evaluations and perceptions of self, ingroup, and outgroup: Comparisons between Mexican-American and European-American children. Self and Identity, 2(3), 203-221. https://doi.org/10.1080/15298860309028

Thomsen, L., Frankenhuis, W. E., Ingold-Smith, M., \& Carey, S. (2011). Big and mighty: Preverbal infants mentally represent social dominance. Science, 331(6016), 477-480. https://doi.org/10.1126/science. 1199198

Thomsen, L. (2020). The Developmental Origins of Social Hierarchy: How infants and young children mentally represent and respond to power and status. Current Opinion in Psychology, 33, 201-208. https://doi.org/10.1016/j.copsyc.2019.07.044

Vasilyeva, N., Gopnik, A., \& Lombrozo, T. (2018). The development of structural thinking 
about social categories. Developmental Psychology, 54(9), 1735. https://doi.org/10.1037/dev0000555

Vasilyeva, N., \& Lombrozo, T. (2020). Structural thinking about social categories: Evidence from formal explanations, generics, and generalization. Cognition, 204, 104383. https://doi.org/10.1016/j.cognition.2020.104383

Walker, C. M., Lombrozo, T., Legare, C. H., \& Gopnik, A. (2014). Explaining prompts children to privilege inductively rich properties. Cognition, 133(2), 343-357. https://doi.org/10.1016/j.cognition.2014.07.008

Walker, C. M., Lombrozo, T., Williams, J. J., Rafferty, A. N., \& Gopnik, A. (2017). Explaining constrains causal learning in childhood. Child Development, 88(1), 229-246. https://doi.org/10.1111/cdev.12590

Wilton, L. S., Bell, A. N., Carpinella, C. M., Young, D. M., Meyers, C., \& Clapham, R. (2019). Lay theories of gender influence support for women and transgender people's legal rights. Social Psychological and Personality Science, 10(7), 883-894. https://doi.org/10.1177/1948550618803608

Yeager, D. S., Hanselman, P., Walton, G. M., Murray, J. S., Crosnoe, R., Muller, C., ... \& Paunesku, D. (2019). A national experiment reveals where a growth mindset improves achievement. Nature, 573(7774), 364-369. https://doi.org/10.1038/s41586-019-1466-y

Zakin, A. (2012). Hand to hand: teaching tolerance and social justice one child at a time. Childhood Education, 88(1), 3-13. https://doi.org/10.1080/00094056.2012.643709 